\title{
How can a binary switch within the pars tuberalis control seasonal timing of reproduction?
}

\author{
Shona H Wood ${ }^{1,2}$ \\ 'Department of Arctic and Marine Biology, UiT - The Arctic University of Norway, Tromsø, Norway \\ 2Faculty of Biology, Medicine and Health, School of Medical Sciences, University of Manchester, Manchester, UK \\ Correspondence should be addressed to S Wood: shona.wood@uit.no
}

\section{Abstract}

Life in seasonally changing environments is challenging. Biological systems have to not only respond directly to the environment, but also schedule life history events in anticipation of seasonal changes. The cellular and molecular basis of how these events are scheduled is unknown. Cellular decision-making processes in response to signals above certain thresholds regularly occur i.e. cellular fate determination, apoptosis and firing of action potentials. Binary switches, the result of cellular decision-making processes, are defined as a change in phenotype between two stable states. A recent study presents evidence of a binary switch operating in the pars tuberalis (PT) of the pituitary, seemingly timing seasonal reproduction in sheep. Though, how a binary switch would allow for anticipation of seasonal environmental changes, not just direct responsiveness, is unclear. The purpose of this review is to assess the evidence for a binary switching mechanism timing seasonal reproduction and to hypothesize how a binary switch would allow biological processes to be timed over weeks to years. I draw parallels with mechanisms used in development, cell fate determination and seasonal timing in plants. I propose that the adult PT is a plastic tissue, showing a seasonal cycle of cellular differentiation, and that the underlying processes are likely to be epigenetic. Therefore, considering the mechanisms behind adult cellular plasticity offers a framework to hypothesize how a long-term timer functions within the PT.

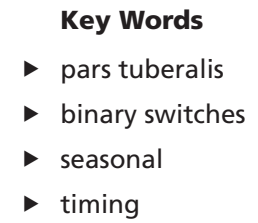

Journal of Endocrinology (2018) 239, R13-R25

\section{Introduction}

Anticipation and responsiveness to environmental signals is key to adapting to a changing environment. Organisms can schedule life history events in order to maximize fitness. For example, timing birth to the season of highest food availability. This is not solely a response to the prevailing environmental conditions but a scheduled/ anticipated event, taking advantage of the predictability of seasonal cycles. These major physiological changes can take weeks to complete; thus, the organism must intrinsically know the time of year and anticipate upcoming conditions. Animals have evolved to use the annual variation in day length (photoperiod), a highly predictive signal, together with endogenous long-term timers ('circannual clock'). Therefore, they keep track of seasonal time, even in constant conditions (i.e. the hibernacula) and activate a seasonal adaptive programme (Lincoln \& Clarke 1994, Lincoln et al. 2005, 2006, Lincoln 2006, Wood \& Loudon 2014, 2017, West \& Wood 2018).

The cellular and molecular basis of how seasonal life history events are scheduled is unknown. Binary decisions are at the core of many different cellular processes, such as cellular fate determination, apoptosis and firing of action 
potentials. These are all regarded as decision-making processes in response to signals above certain thresholds, which leads to all-or-nothing activation of downstream pathways. Thresholding of responses is an important way to properly space biological events and is seen during the accurately timed process of embryonic development (Ashe 2006, Chattwood et al. 2013). Developmental changes are characterized by binary switching of cellular phenotype from one stable state to another. A recent study presents evidence of a binary switch operating in the PT of the pituitary, seemingly timing seasonal reproduction (Wood et al. 2015). The purpose of this review is not to extensively review the seasonal field (for extensive reviews see: Dardente et al. 2014, Nakane \& Yoshimura 2014, Wood \& Loudon 2014, 2017), instead I will review the evidence for a binary switching mechanism in the PT. I shall draw parallels with mechanisms used in development, cell fate determination and seasonal timing in plants. Finally, I will hypothesize how a binary switch would allow biological processes to be timed over weeks to years.

\section{The photoperiodic response}

Nocturnal secretion of pineal melatonin acts as a critical transducer of photoperiod change, providing the brain with an internal hormonal representation of external photoperiod (Fig. 1, reviewed in Hazlerigg \& Loudon 2008, Dardente et al. 2014, Nakane \& Yoshimura 2014, Wood \& Loudon 2014, 2017, West \& Wood 2018). The PT is the only consistent site of melatonin binding in a wide range of seasonally breeding mammalian species (Morgan et al. 1994). It impinges on the hypothalamopituitary axis and governs both an anterograde (prolactin) and retrograde (TH) pathway to the pars distalis and hypothalamus, driving seasonal physiological adaptations (Wood \& Loudon 2017, Korf 2018). Here, I focus on the better characterized photoperiodic thyroid hormone (TH) pathway relating to seasonal reproduction.

The PT-specific thyrotrophs contain receptors for melatonin (Klosen et al. 2002, Dardente et al. 2003, Johnston et al. 2006), which govern the local release of thyroid-stimulating hormone (TSH) (Dardente et al. 2010). The photoperiodic control of TSH production depends on upregulation of TSH $\beta$ subunit by the transcriptional co-activator, EYA3 on long photoperiods ('LP induction') (Dardente et al. 2010, Masumoto et al. 2010). PT TSH signals to hypothalamic tanycytes, which in turn modulate the seasonal biological availability of $\mathrm{TH}$, via the expression of deiodinase enzymes (DIOs).

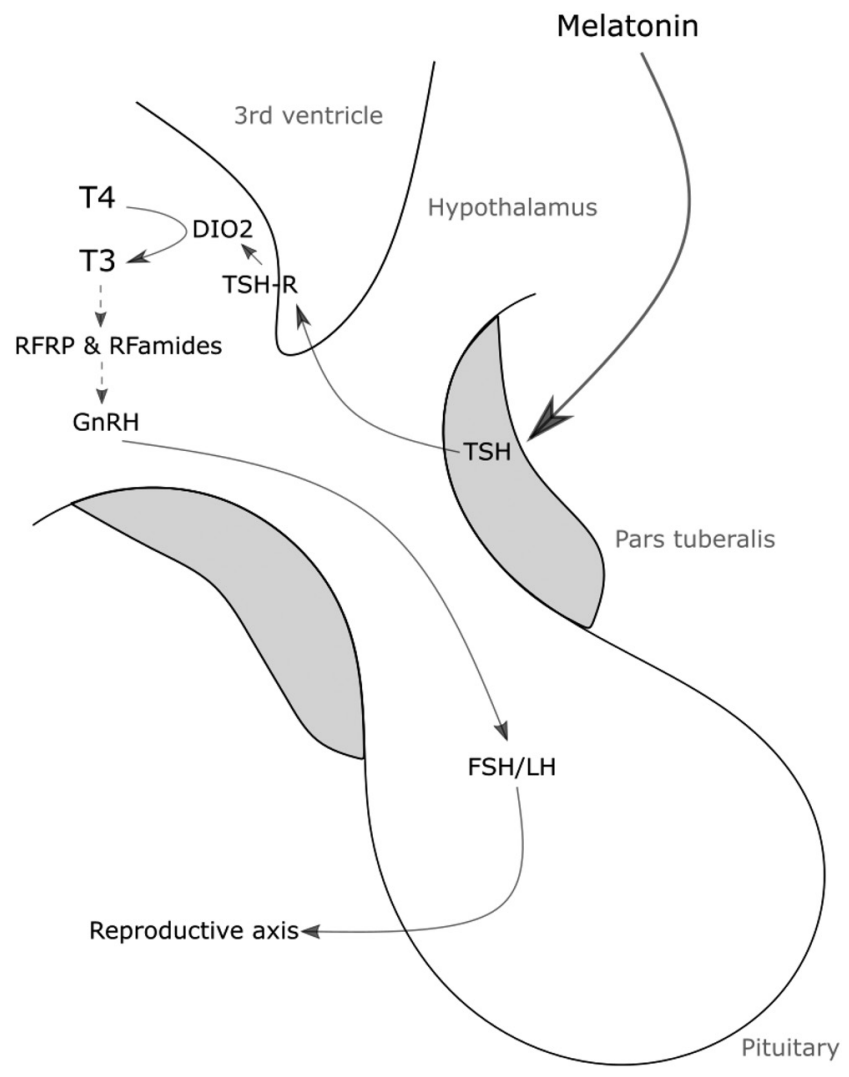

Figure 1

Retrograde action of TSH on ependymal cells in the hypothalamus. Photoperiod is encoded by the nocturnal melatonin signal that is sculpted by day length, generating short-duration signals in response to long photoperiod (LP) conditions. The prime site of action is the pituitary pars tuberalis. LP activation of TSH $\beta$ leads to an increase in deiodinase 2 (DIO2) activity in adjacent ependymal cells (tanycytes), which express the TSH receptor. DOI2 converts inactive $\mathrm{T}_{4}$ to active $\mathrm{T}_{3}$. Rfamides (including KISS-1) and RF-related peptides serve as neuroendocrine intermediates in the regulation of reproduction across taxa and their regulation is altered in response to photoperiod (reviewed in Kriegsfeld 2006, Simonneaux et al. 2013). It has shown that $\mathrm{T}_{3}$ regulates the expression of RFRP and KISS-1 (Henson et al. 2013), potentially via TSH (Klosen et al. 2013) but the mechanism of $\mathrm{T}_{3}$ action is uncertain. RFRP has been noted to have high expression in LP and a low expression in SP, regardless of breeding season. It has been suggested that RFRP subsequently acts either directly on GnRH neurons or indirectly via kisspeptin $(\mathrm{kp})$ neurons or other interneurons in the arcuate nucleus (ARC) to synchronize reproduction with season in a species dependent manner (reviewed in Henningsen et al. 2016).

The DIOs convert $\mathrm{T} 4$ to active $\mathrm{T} 3$ (DIO2) and T4 to inactive reverse T3 (DIO3) (Dardente et al. 2014). Hypothalamic T3 status controls central structures involved in seasonal metabolic physiology and reproduction (Murphy et al. 2012, Klosen et al. 2013, Bank et al. 2017). Reproductive effects are mediated through alterations in the GnRH pulse generator, potentially involving kisspeptin and RFRP3 (Simonneaux et al. 2013, Hazlerigg \& Simonneaux 2015, Beymer et al. 2016) (Fig. 2). The EYA3/TSH/DIO 


\begin{tabular}{l|l|l|l|l|} 
Journal of & S Wood & Seasonal binary switches & $\mathbf{2 3 9 : 1}$ \\
Endocrinology & &
\end{tabular}

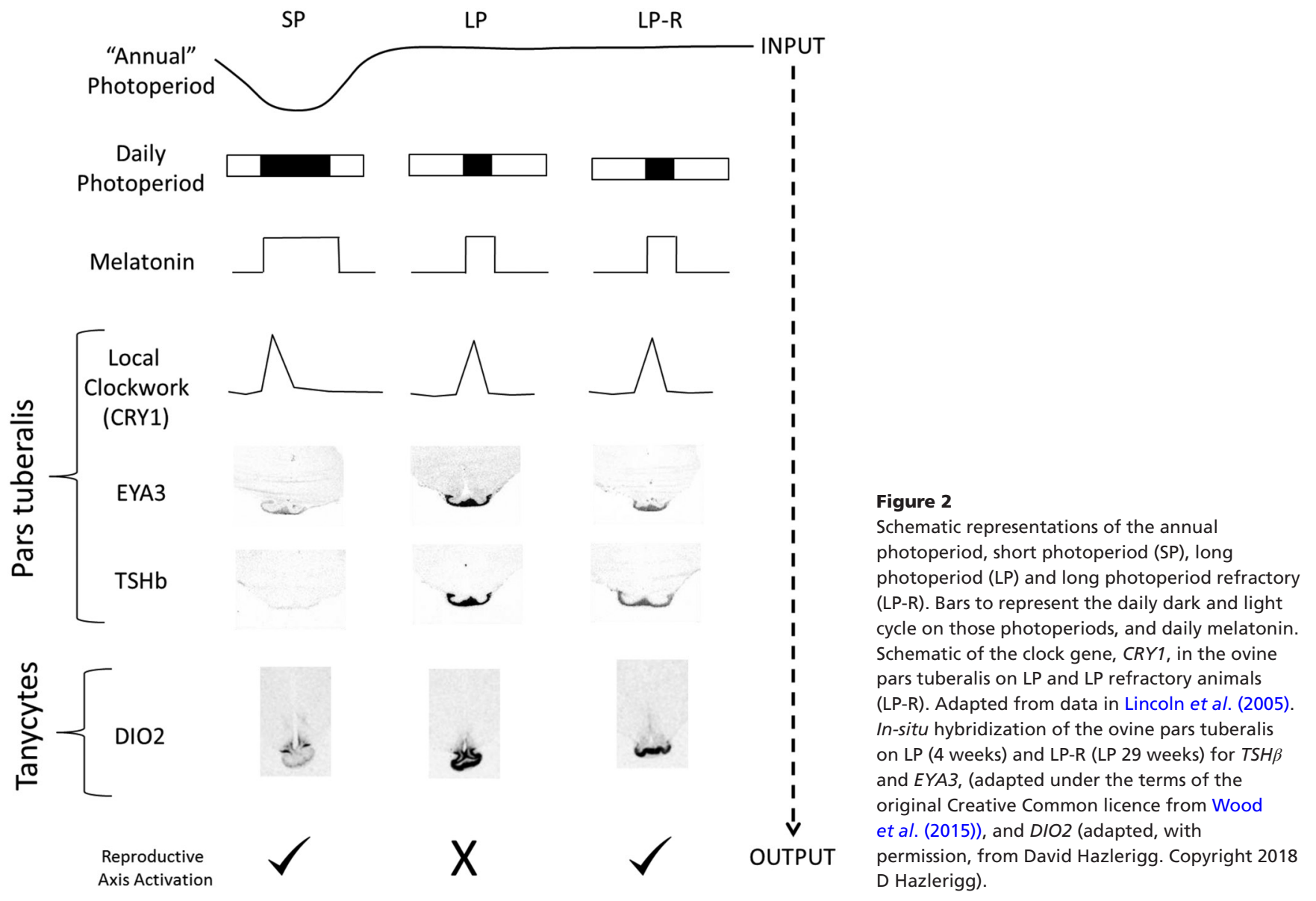

photoperiodic switch is highly conserved amongst vertebrates (Nakane \& Yoshimura 2014), but PT tissue is not conserved in lower vertebrates i.e. fish (Lincoln et al. 2003, Wood \& Loudon 2017).

Here, I focus on the PT-specific thyrotroph as point of initiation of the physiological change but also the site showing spontaneous reversion suggesting it is the site of endogenous long-term timekeeping (see below) (Lincoln et al. 2003, 2006, Wood \& Loudon 2017). However, I note that in mammals, photoperiodic information is transferred from mother to pup and that photoperiodic history dependence is seen in the hypothalamic tanycytes, not the PT (Sáenz de Miera et al. 2017). Therefore, both the PT and the hypothalamic tanycytes are critical sites of photoperiodic history, circannual cue integration and transmission to the endocrine and central nervous systems (Lincoln et al. 2006, Sáenz de Miera et al. 2014, Wood \& Loudon 2014, 2017, Wood et al. 2015).

At a PT tissue-level, TSH $\beta$ progressively increases in RNA expression over the first 4 weeks of LP (Wood et al. 2015) (Fig. 3A), but the increase in expression is already beginning 3 days after the switch to LP in sheep (Dardente et al. 2010) and the F344 rat (Ross et al.
2011). In fact, from the first long day increased TSH $\beta$ is observed in quail (Nakao et al. 2008), chicken (Dunn et al. 2017) and the bunting (Majumdar et al. 2014). This suggests a direct responsiveness and transcriptional activation and is referred to as 'LP induction', but it is important to remember this can only occur if the animal has experienced an appropriate duration of winter/ short photoperiod signal and that the TSH $\beta$ signal is not maximal until 4 weeks of LP in sheep.

The tissue response of TSH $\beta$ in the PT is seemingly consistent with progressive changes in sheep $\mathrm{LH}$ and FSH under natural photoperiods (Billings et al. 2002, Lomet et al. 2018) and square wave transitions (Bittman et al. 1983), leading to the downstream reproductive changes. However, the correlations between in DIO/TSH and LH/FSH in hamsters are not so clear, especially when considering refractory animals (see below), potentially implicating the tanycytes as important modulators of the refractory response in hamsters (Milesi et al. 2017). Though, a directly correlative approach to causality is not necessarily appropriate when dealing with autoregulatory feedback loops across tissues. Therefore, I will focus on how these gradual tissue-level responses may be 
A

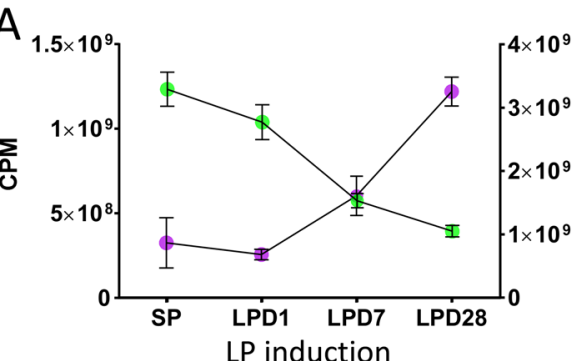

C

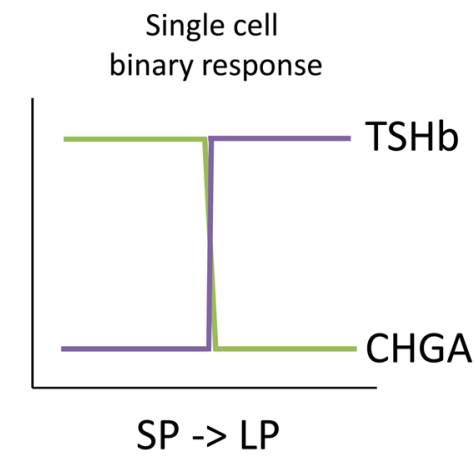

B

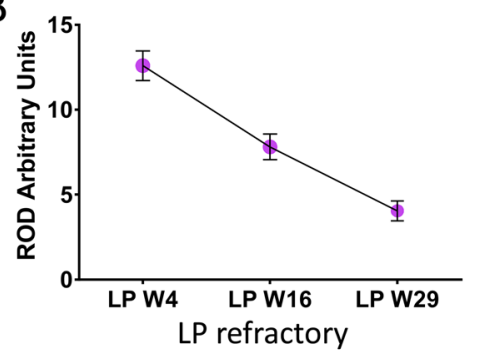

Tissue progressive response

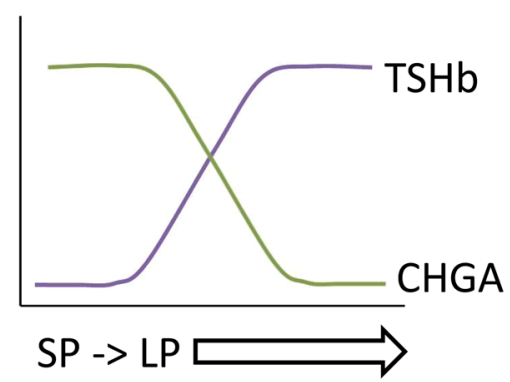

D

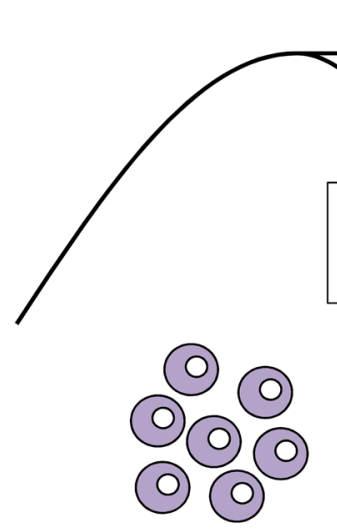

TSHb+ve
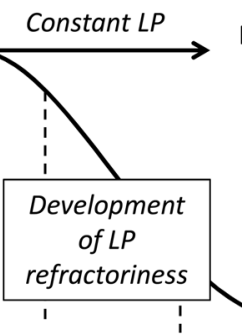

Reversion to

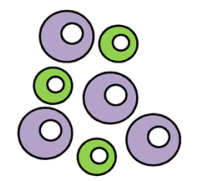

TSHb+ve/ CHGA+ve winter phenotype

phenotyp

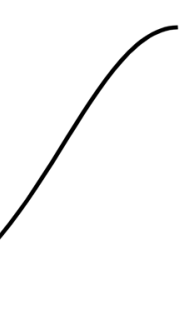

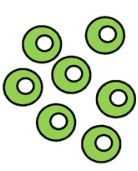

CHGA+ve

generated in the PT to suggest how this tissue can act as an endogenous timer.

\section{Endogenous timekeeping: scheduling and anticipation of events}

The amount of light taken from a single day is indistinguishable from a matched point in autumn or spring; thus, for photoperiodic information to be meaningful, it must be registered within the context of recent preceding photoperiods (Butler et al. 2010, Sáenz de Miera et al. 2017, West \& Wood 2018). Therefore, life history trajectories and seasonal programmes are set depending on the prior photoperiodic history. Importantly, the observed acute inductive effects of LP

\section{Figure 3}

(A) RNA-seq normalized counts per million displaying the amount of TSH $\beta$ (purple) and CHGA (green) transcript in the first 4 weeks of LP; SP, short photoperiod; LPD1, 1st day of long photoperiod; LPD7, 7th day of long photoperiod; LPD28, 28th day of long photoperiod. Data from Wood et al. (2015). (B) In-situ hybridization quantification for TSH $\beta$ (purple) after 4 weeks (LPW4), 16 weeks (LPW16) and 29 weeks (LPW29) of long photoperiod. Data from Wood et al. (2015). (C) Schematics showing the difference in a single-cell binary response, which can occur at a variable length of time from the LP switch and a tissue progressive response, slowly accumulating over time in LP. (D) The model proposes that an endogenous timer switches TSH $\beta$ expression in the PT thyrotroph cells, driving TSH and hypothalamic thyroid hormone metabolism independently of photoperiod. Individual PT thyrotroph cells are either in a long (TSH $\beta+$ ) or short ( $\left.\mathrm{CHGA}_{+}\right)$photoperiod state, and the relative proportion of these binary-state cells determines the phase of the circannual cycle and the subsequent reproductive physiology. Data from Wood et al. (2015). Adapted under the terms of the original Creative Commons licence from Dardente (2015). are only able to occur if the appropriate prior history has been experienced (reviewed in: West \& Wood 2018). This demonstrates that the photoperiodic response is not a direct/immediate response to any photoperiod change but is a scheduled/anticipated responsiveness to ensure physiological changes occur at the appropriate time of year.

Changes in seasonal physiology can persist in constant conditions, and even in the absence of a pineal gland (Woodfill et al. 1994, Sáenz de Miera et al. 2014). These rhythms are no longer entrained to the solar year but proceed according to the prior photoperiodic history. In short-lived species, these rhythms only revert once and usually lead to the animal being locked on a reproductive phenotype (refractory). Long-lived species 
show a persistence of rhythms for many years in constant conditions (circannual rhythms) (Gwinner 1986). In either case, there is endogenous timing resulting in spontaneous changes in seasonal physiology.

To understand the mechanisms animals use to anticipate seasonal environmental changes and respond appropriately, we must consider where in the photoperiodic TH pathway the endogenous timer acts. By placing sheep into constant LP, we can reveal the circannual rhythm and assess the known photoperiodic circuits (Fig. 2). Here, both the melatonin signal and the local circadian clockwork in the PT does not change, continuing to reflect the prevailing photoperiod (Lincoln et al. 2002, 2005) but EYA3/TSH/DIO do spontaneously revert in constant conditions, tracking the cycles of seasonal physiology of the animal (Sáenz de Miera et al. 2013, Wood et al. 2015). DIO and TSH $\beta$ reversion have also been demonstrated in European hamsters (Sáenz de Miera et al. 2014).

PT TSH $\beta$ progressively declines on constant LP (Sáenz de Miera et al. 2013, Wood et al. 2015), tracking the circannual cycle of reproductive physiology, referred to as the 'LP refractory' state (Figs 2 and 3B). This decline is also observed under natural photoperiod between May ( $14.5 \mathrm{~h}$ light) and August ( 14.5 h light), representing only an hour and a half decline from solstical photoperiod i.e. still a LP (Lomet et al. 2018). Importantly, TSH $\beta$ is not the only PT-expressed gene to change after constant LP (Wood et al. 2015, Lomet et al. 2018), but it serves as a good marker for the LP physiological state and currently provides the best causal link to seasonal reproductive changes (Hanon et al. 2008).

LP induction appears to be well synchronized between individual animals, whereas the LP refractory decline (when animals are kept on constant LP) is variable amongst individual animals. This is unsurprising given the lack of a synchronising signal from a photoperiodic change. During LP induction at a cellular level, there may be greater synchronization potentially leading to a more consistent output. If the cells are synchronized, two possibilities exist for how this gradual tissue response is generated during LP induction: (1) all the thyrotrophs within the tissue progressively increase the expression of TSH $\beta$ from the time of the LP switch. Or (2) individual thyrotrophs 'switch on' TSH $\beta$ expression at different rates once exposed to LP. For option 2, variation in threshold of responses in individual cells would lead to the gradual accumulation in the number of TSH $\beta$-expressing cells after LP induction. These options represent the difference between a whole tissue response and a single-cell response that accumulates into a tissue-level output (Fig. 3C). But what evidence is there that there are individual cell switches in response to photoperiod?

\section{Binary switch within the PT}

Mathematical modelling of the photoperiodic response predicted a switching of cellular phenotype in the PT in response to photoperiod (Ebenhöh \& Hazlerigg 2013) but without identification of a cellular marker of short photoperiod (SP - 'winter'), this could not be tested. A large transcriptomic dataset on the sheep PT, allowed the identification of the SP marker, chromogranin A (CHGA) (Wood et al. 2015). CHGA, a hormone packaging molecule, strongly co-localizes to the secretory granules in PT-specific thyrotrophs in SP and displays the progressive tissue-level response, contrasting to the LP signal TSH $\beta$ (Fig. 3A) (Wood et al. 2015). Unlike TSH $\beta$, the role for CHGA in a seasonal context is unknown, but the increase in expression corresponds to a decrease in rough endoplasmic reticulum (RER) and a decrease in secretion from these cells (Wood et al. 2015). However, prolactin was the hormone output monitored in this study, due to castrate male being used; therefore, it cannot be directly linked to reproductive outputs (Wood et al. 2015).

Using CHGA as a marker for the 'winter' state and TSH $\beta$ protein expression as a marker for the 'summer' state, the distribution of individual PT thyrotroph cells were mapped at 4-week LP, SP and 29-week LP (LP refractory). This revealed that virtually no PT-specific thyrotrophs (defined by $\alpha \mathrm{GSU}$ expression) co-express both CHGA and TSH $\beta(0.01 \%-2$ cells out of 17,000) (Wood et al. 2015), indicating that PT thyrotrophs can only exist in one of two binary states, winter-like (CHGA+ve) or summerlike (TSH $\beta+v e)$. Importantly, this switching occurred at 29-week LP (LP refractory), reverting to the winter-like state, demonstrating that it occurs as an endogenously timed process (Wood et al. 2015) (Fig. 3B and D). The possibility that these observations were due to two different cell populations i.e. LP and SP specialized subsets of PT-specific thyrotrophs was considered. Cell counts revealed that in SP 4 weeks nearly all (91.6\%) PT-specific thyrotrophs expressed CHGA and in LP 4 weeks $66.6 \%$ of PT-specific thryotrophs expressed TSH $\beta$ (approx. 5\% still express CHGA and the remainder only expressing $\alpha \mathrm{GSU}$ ); therefore, the most likely explanation is that within a population of PT-specific thyrotrophs, cells switch from one phenotype to another (Wood et al. 2015). To add to that conclusion we and others have demonstrated 
that cell division in the PT is very low $(<0.2 \%)$ and not within the PT-specific thyrotroph population (Migaud et al. 2011, Hazlerigg et al. 2013, Wood et al. 2015). Also the RNA expression of $\alpha G S U$ did not change, nor did the expression of established cell cycle genes (Wood et al. 2015). We cannot completely rule out that these observations are due to the presence of two different cell populations without cell fate mapping approaches, which are currently not tractable in seasonal model species. These observations have only been made in sheep, in this one study, and unfortunately, an individual cell level characterization has not been made at different points of the seasonal cycle.

Nevertheless, a binary switch has good explanatory value for the progressive tissue-level changes observed and subsequent cycles of physiology that occur and may provide a framework to understand seasonal timekeeping. To hypothesize how a binary switch could operate to time biological processes over weeks to years we would need to know: (1) What initiates the binary switch (LP induction), (2) How the cycle is endogenously generated (LP refractory), (3) What is the basis of individual cell variability in response and (4) What is the role of input history (prior photoperiod).

\section{Initiating the binary switch: a seasonal differentiation process?}

The PT has a distinct developmental origin from the rest of the pituitary gland, and it emerges from the rostral tip region of Rathke's pouch. The bHLH transcription factor hairy enhancer of split (HES1) is a PT-specific differentiating factor (Akimoto et al. 2010, Aizawa et al. 2016). All glycoprotein hormones comprise a common $\alpha$ subunit ( $\alpha \mathrm{GSU}$ ) and a specific $\beta$ subunit $(\beta F S H / \beta L H / \beta T S H)$. In embryological development, $\alpha \mathrm{GSU}$ is the first subunit gene expressed in the pituitary (Stoeckel et al. 1993, Kameda et al. 1998, Kita et al. 2007, Raetzman et al. 2007, Akimoto et al. 2010, Inoue et al. 2013). CHGA (with $\alpha G S U$ ) appears just prior to TSH $\beta$ in embryonic development of the mouse pars distalis (Akimoto et al. 2010) and is an early embryonic signal in zebrafish (Xie et al. 2008) and the chicken PT (Kameda et al. 1998). In the main pituitary upon differentiation to specific endocrine cell types, expression of the $\beta$ subunit is gained in adult endocrine cells. In this context, adult PT-specific thyrotrophs are unique since they persist as $\alpha \mathrm{GSU}+$ precursors, and only mature into $\alpha \mathrm{GSU} / \mathrm{TSH} \beta$ expressing thryotrophs when exposed to LP. Therefore, by definition, the PT-specific thyrotroph appears to undergo a seasonal cycle of differentiation/maturation on exposure to LP, essentially undergoing a seasonal recapitulation of a developmental state, to drive seasonal physiological changes.

Differentiation dramatically changes a cells size, shape, metabolic activity and responsiveness to signals. Therefore, changes in gene expression and morphology are used to define differentiation. Within the sheep PT, two large scale transcriptomic analysis clearly illustrate that genes related to development, cytoskeletal remodelling and tissue plasticity are enriched on LP (Wood et al. 2015, Lomet et al. 2018). PT thyrotrophs increase in size, increase RER, gain a secretory phenotype and reorganize into networks on LP, presumably to coordinate the secretion of TSH (Wood et al. 2015) (Fig. 4A). Differentiation can occur without cell division (O'Neill \& Stockdale 1972, Yang et al. 2007), which may be consistent with the lack of evidence for cell division in the PT thyrotroph (Migaud et al. 2011, Hazlerigg et al. 2013, Wood et al. 2015). This ability to differentiate without division has been suggested to allow for faster responses to signals (Yang et al. 2007). In the context of the PT, it is possible that over winter PT thyrotrophs are 'primed' to respond to an LP signal, explaining the rapid production of TSH $\beta$ during LP induction. Therefore, I propose that the binary switch is initiated by a seasonal differentiation of PT thyrotrophs to a mature TSH-secreting state.

A seasonal cycle of differentiation would require a differentiation signal/factor that is expressed on LP. A more detailed analysis of published data on the first, seventh and 28th day of LP, shows 24 genes changing within the PT on transition to LP were related cellular differentiation and cell cycle (Wood et al. 2015). KLF11, TRIM2 and EYA3 have a pattern of expression that would be consistent with a transient LP differentiation signal and a progressive accumulation of TSH $\beta$-positive cells (Fig. 4B). KLF11 has roles in the differentiation of adipocytes to brown fat (Loft et al. 2015) and the differentiation of pancreatic progenitor cells (Teo et al. 2018). TRIM2 regulates neuronal differentiation (Khazaei et al. 2011) and epidermal and hair follicle differentiation (Joost et al. 2016). Due to the difficultly in the dissection of the PT, it is possible that some median eminence or pars nervosa was in the sample; therefore, it remains to be shown if either TRIM2 or KLF11 have a PT-specific expression. EYA3 does have specific PT expression (Fig. 2A), and, has an extensively documented role in retinal, pituitary and muscle development and differentiation (Xu et al. 1997, Jemc \& Rebay 2007, Kozmik et al. 2007, Kumar 2009, Gordon et al. 2012, Tadjuidje \& Hegde 2013). In the context of seasonal 
A

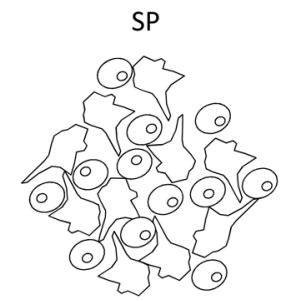

B

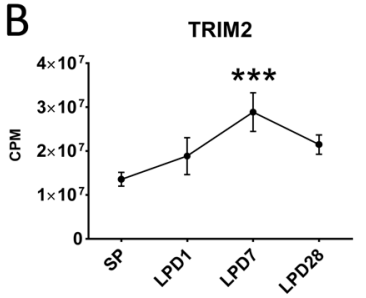

LP

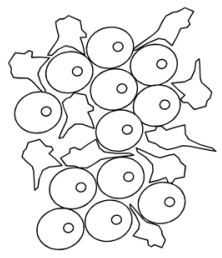

KLF11

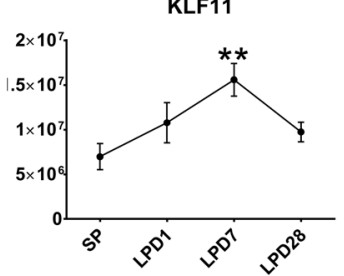

LP-R
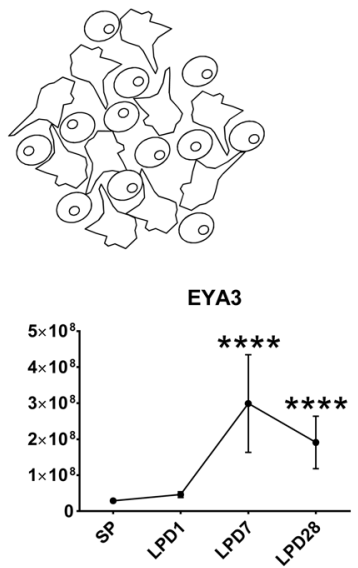

C

Stem cells

Progenitor cells

Mature cells

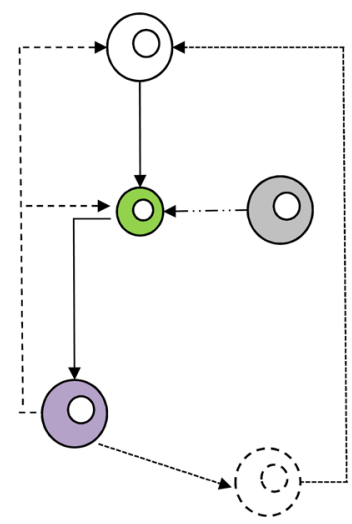

$\longrightarrow$ Differentiation

-.-.-. De-differentiation

$\longrightarrow \cdots-\cdots \rightarrow$ Trans-differentiation

$\longrightarrow-----\rightarrow-\rightarrow$ Death and replacement

(2) Resident/embryonic stem cell

(C) Infilterating cell (CD45+)

(?) CHGA+ cell

(O) $\mathrm{TSHb}+$ cell

(i) Cell death
D

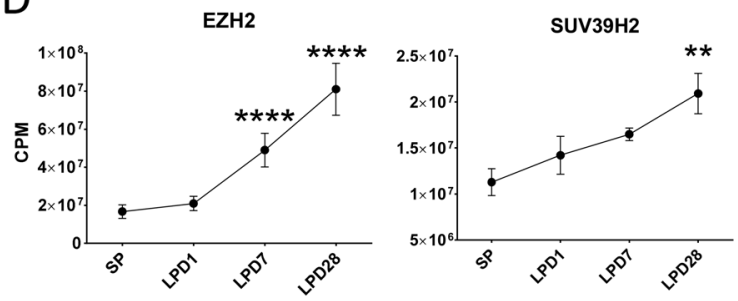

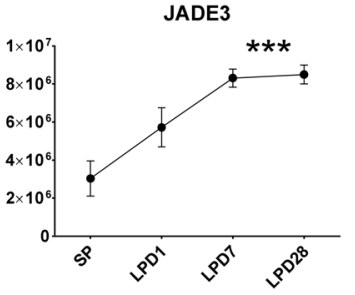

Figure 4

(A) Seasonal remodelling of the pars tuberalis. Diagrams representing the tissue-level changes are below. SP and the LP-R state are characterized by a FS cell network, separating individual PT-specific thyrotrophs. LP is characterized by larger PT thyrotrophs remodelled into an integrated network. Adapted from: Wood et al. (2015). (B) RNA-seq normalized counts per million displaying the amount of TRIM2, KLF11 and EYA3 transcript in the first 4 weeks of LP; SP, short photoperiod, LPD1, 1st day of long photoperiod; LPD7, 7th day of long photoperiod; LPD28, 28th day of long photoperiod. * denotes FDR less than $0.01 ; * * 0.001 ; * * * 0.0001 ; * * * *<0.00001$. Data from Wood et al. (2015). (C) A model for the binary switch. Demonstrating the differences between differentiation, de-differentiation, transdifferentiation and death and replacement. (D) RNA-seq normalized counts per million displaying the amount of $E Z H 2$, SUV39H2 and JADE3 transcript in the first 4 weeks of LP; SP, short photoperiod; LPD1, 1st day of long photoperiod; LPD7, 7th day of long photoperiod; LPD28, 28th day of long photoperiod. * denotes FDR less than $0.01 ; * * 0.001 ; * * * 0.0001$;

$* * * *<0.00001$. Adapted under the terms of the original Creative Commons licence from Wood et al. (2015). biology, EYA3 is emphasized to be a clock-dependent transcriptional co-activator of TSH $\beta$ (Dardente et al. 2010, Masumoto et al. 2010, Wood \& Loudon 2014), not a cellular differentiation signal. However, after 4 weeks of LP in sheep only $38 \%$ of TSH $\beta$-expressing cells also express EYA3 (Wood et al. 2015). Another study recently noted a lack of an Eya3-Tsh $\beta$ relationship (Hazlerigg et al. 2018). This suggests that EYA3 is not the sustaining signal for $\mathrm{TSH} \beta$ expression. Finally, the TSH receptor is required to sustain TSH $\beta$ expression (Ono et al. 2008), suggesting positive feedback of TSH and transience of EYA3. A role for EYA3 as a seasonal differentiation signal is feasible, but remains to be demonstrated (Fig. 4C).

$\begin{array}{lr}\text { http://joe.endocrinology-journals.org } & \text { ○ } 2018 \text { Society for Endocrinology } \\ \text { https://doi.org/10.1530/JOE-18-0177 } & \text { Published by Bioscientifica Ltd. } \\ & \text { Printed in Great Britain }\end{array}$

\section{An endogenous cycle of binary switching: seasonal de-differentiation or death?}

If PT thyrotrophs do differentiate to a mature TSHproducing cell type then an explanation for the reversion to a $\alpha G S U$-positive cell that is phenotypically characteristic of an immature endocrine cell during the LP refractory state and over a natural seasonal cycle is required. I suggest there are three possibilities: (1) A subsequent reversion to an immature/progenitor state (de-differentiation); (2) Trans-differentiation from a different mature cell type or (3) A cycle of death and replacement (Fig. 4C). 
Traditionally, cell fate determination has been viewed as a process of progressively increasing restriction of cellular fate potential on the path to a fully mature differentiated cell. Recent studies have highlighted possibility that cells do not assume fixed final differentiated phenotypes in adult tissues. This plasticity of differentiated cells is likely to be central to survival through rapid response to injury or environmental changes (Paksa \& Rajagopal 2017). The reversion of a PT-specific thyrotroph to a progenitor or SP (winter-like) state via de-differentiation is potentially the most parsimonious explanation in the PT (Fig. 4C). There is precedence for this, pancreatic $\beta$-cells in type 1 diabetes, de-differentiate (Talchai et al. 2012, Cinti et al. 2016) and insulin therapy re-differentiates these cells (Wang et al. 2014). Therefore, adult endocrine cells can undergo cycles of differentiation and de-differentiation.

Trans-differentiation (lineage reprogramming) suggests that a mature cell becomes a different cell type. For example, mature $\delta$ cells in the pancreas and hepatocytes in the liver converting to $\beta$-cells and biliary epithelial cells, respectively. The most common example of trans-differentiation is limb regeneration in amphibians (reviewed in: Shen et al. 2004, Cai et al. 2007). These examples indicate that by changing the environment of the cell, there can be a reprogramming of fate (Paksa \& Rajagopal 2017). However, the difference between de-differentiation and trans-differentiation becomes less clear when the majority of evidence points to differentiated cell, de-differentiating to a progenitor or stem cell phenotype, and then re-differentiating to a different mature cell type (Cai et al. 2007). In the context of the PT, and the strictest definition of transdifferentiation, the presence of an infiltrating (or resident) cell type that switches fate would be required. One study observed the presence of dividing CD45-positive cells with a microglia phenotype in the PT (Hazlerigg et al. 2013), there was no seasonal variation in the numbers of cells observed, but these could represent a candidate cell for trans-differentiation. SRRM4 shows transcriptional changes in the PT on LP (Wood et al. 2015) and is known to drive neuroendocrine trans-differentiation of prostate adenocarcinoma cells (Li et al. 2017), potentially providing a candidate gene, but it is difficult to draw conclusions from data on a mixed cell population.

Finally, a cycle of death and replacement (from a stem cell population) generating a circannual rhythm (seasonal histogenesis) was proposed before the observation of a binary switch (Hazlerigg \& Lincoln 2011). Seasonal histogenesis could provide a mechanism to explain loss and replacement of TSH-positive cells within the PT. But there have been few studies of cell turnover in the
PT, and these do not present a consistent picture as to the extent to which cell division varies with seasonal state (Migaud et al. 2011, Hazlerigg et al. 2013, Wood et al. 2015). In the context of a cycle of de-differentiation the capacity to gain proliferative function is a characteristic of Schwann cells, kidney cells and Sertoli cells following insult (Shen et al. 2004, Cai et al. 2007). Therefore, de-differentiation and histogenesis are not mutually exclusive explanations. Seasonal histogenesis remains to be adequately tested in the PT and would require assessment of cell death and division.

I have provided a potential framework to address how the seasonal cycle of binary switching may operate in the PT but I have not offered an explanation for how this would allow for long-term timekeeping. I propose that individual cell variation in the threshold of responsiveness and variation in the subsequent reversion could generate a timer process.

\section{The role of individual variability in accurate timing}

Endocrine cells have acute, medium and long-term outputs, and these must be regulated across different time scales and in response to diverse environmental signals, whilst achieving accurate control of hormone expression. At first glance, the idea of individual cell variability to environmental signals may seem to be contrary to accuracy and control of hormone expression. However, stochastic heterogeneity in single-cell response can lead to tissue progressive responses. Release of prolactin from the pituitary, for example, is based on heterogeneous patterns of gene expression at a single-cell level but a wellregulated average level of gene expression is maintained (Featherstone et al. 2011, Harper et al. 2011). Prolactin expression follows a binary 'on-off' process, with activity of individual cells being unpredictable, but the overall activity of a group of cells being predictable (Hey et al. 2015, Featherstone et al. 2016). The conclusions from these study were that heterogeneous single-cell responses allowed the tissue to be more functionally adaptive to the environment and result in more robust tissue-level responses, avoiding inappropriate amplification of signals through feedback mechanisms (Featherstone et al. 2011, 2012, 2016, Harper et al. 2011, Hey et al. 2015).

During development, pluripotent cells differentiate and become restricted to specific lineages. Often, this depends on positional information and morphogenic gradients, the clear banding (position-effect variegation) seen in the Drosophila embryo is a good example, but there 
are also examples of position-independent patterning (Kay $\&$ Thompson 2009). Position-independent patterning is characterized by cells switching or differentiating from one phenotype to another in an apparently stochastic manner, with variability in timing, across the tissue. Position-independent patterning makes it appear as if two cells types are randomly 'sprinkled' throughout a tissue, and for that reason, it is referred to as, salt and pepper differentiation. Re-patterning is also a feature of this process, as seen in the PT (Fig. 4A). Examples of this include the early mouse embryo, and the R8 photoreceptor neurons in Drosophila that differentiate into rhodopsin 5-sensitive or rhodopsin 6-sensitive subtypes through stochastic expression of specific transcription factors determining cell (Eldar \& Elowitz 2010, Jukam et al. 2013). This stochasticity is presumed to add robustness and accuracy to timing of differentiation during development (Kay \& Thompson 2009, Eldar \& Elowitz 2010, Jukam \& Desplan 2010, Jukam et al. 2013). Importantly, many terminal differentiation processes show variability in the time from sensing the initial inducing signal to the final commitment to their new fate, this allows cells to defer commitment, which prevents responses to transient signals. In the context of the PT, differences in sensitivity to melatonin and variability in the rate of commitment, may be a mechanism to allow a long-term timer process.

\section{Input history: how is individual variability encoded?}

Within the PT we expect individual variability in the responsiveness to LP, whereby, PT thyrotrophs differentiate into a mature TSH-secreting state (LP induction), but, also in the reversion to winter phenotype (LP refractory). Individual variability may arise through and be modulated by (1) input history to the cell affecting the threshold sensitivity of that cell, and, (2) individual differences in sensitivity and therefore, the rate of commitment.

Vernalization is the process of preparation for flowering, which depends on cold temperatures being experienced for a suitable length of time to permit flowering on rewarming (spring). It is characterized by a progressive binary switching of cells, in a salt and pepper fashion (see above) based on individual variation in responsiveness. Cells progressively switch over weeks of cold exposure, acting as a long-term timer, and only giving a full flowering response when the majority of cells have flipped in state (Angel et al. 2011, Song et al. 2012). Importantly, the input history, in this case low temperature, is key to 'priming' cells to respond to a spring signal. This priming is achieved by a long-term epigenetic repressive process is initiated at the beginning of winter. Prolonged cold in the winter leads to the accumulation of repressive marks mediated by polycomb complex proteins acting on the flowering control locus (FLC), which usually blocks the activation of flowering locus $\mathrm{T}$ (FT). The longer the exposure to cold, the greater the number of cells entering an FLC-repressed state, therefore upon rewarming FT is activated and flowering can occur, with the extent of flowering based on the number cells in the FLC-repressed state (Angel et al. 2011, Andrés \& Coupland 2012, Song et al. 2013). Therefore, plants have a seasonal timer based on binary switching, regulated by chromatin accessibility, which is dependent on duration of cold exposure.

As stated earlier, on natural photoperiod in sheep, TSH $\beta$ begins to decline whilst still on LP (Lomet et al. 2018); similar results have been seen in Siberian hamsters but only assessed at the DIO2 level (Petri et al. 2016). Comparing the gonadal responses of quail and starlings, quail faithfully track the natural photoperiod, but starlings begin to regress their gonads whilst on LP (Dawson 2015). This suggests that LP induction not only leads to a simultaneous activation but also an initiation of long-term repressive process leading to the LP refractory state (Dawson 2015). If this is the case, we need to consider how cells are primed to respond to an LP signal and how they are eventually 'shut down'. I propose two possibilities: (1) Chromatin is maintained in a permissive or primed state and the thyrotrophs can always respond to an LP signal if the transcription factors are present, or, (2) chromatin accessibility is limited to prevent early responses to LP signals and/or to shut down responses after a prolonged period in LP.

Possibility 1 is based on cell fate of the adult intestine. Here, the positioning of the cell in the crypt determines the cell fate and the cells exist as multipotent stem cells, with a broadly permissive chromatin state, meaning that there are multiple possible pathways of differentiation depending on the transcription factors present. Therefore, chromatin state is not the determining factor for cell fate, merely permissive to either fate depending on the transcription factors available (Paksa \& Rajagopal 2017). If in the PT thyrotroph, the chromatin was maintained in a permissive state, as in the intestine, then you would expect all PT thyrotrophs to respond at the same time to any LP signal regardless of the circannual phase. This seems unlikely as there is a known requirement for a winter in order to respond appropriately to an LP signal and the observations of a progressive tissue-level response do not support this. 
Possibility 2 is based on a vernalization model where there would be preparation or priming of PT thyrotrophs to respond to LP over winter, and/or, the initiation of a longer-term repressive process on LP leading to the disappearance of TSH $\beta$ cells. The targets of this proposed limited chromatin accessibility could be EYA3 or regulators of EYA3. Priming to over winter suggests a prolonged winter would synchronize all cells to respond immediately to LP. Given the earlier discussions of the importance of a robust, non-spurious response, it seems possible that even when primed, these cells will have different sensitivity thresholds and therefore individual variance in responsiveness, as demonstrated in cell fate determination in development (Eldar \& Elowitz 2010). Differences in individual cell sensitivity to signals has also been shown in Dictyostelium (slime mould), here, 'cells exhibit different intrinsic response biases or discrete transcriptional activation thresholds to signals' resulting in salt and pepper differentiation (Chattwood et al. 2013).

Whether timing is conferred by cyclical changes in chromatin accessibility remains to be demonstrated, and it is possible that, upstream regulators of specific transcription factors, not the known key circuits, are targets of this cyclical chromatin remodelling. Evidence for seasonal changes in epigenetic state within the PT are limited to the identification of differentially regulated transcripts of known epigenetic modulators (Wood et al. 2015, Lomet et al. 2018). EZH2, a member of the PRC2 complex that lays down the repressive H3K27me3 mark during development, is upregulated in the PT in LP (Wood et al. 2015, Lomet et al. 2018) (Fig. 4D). EZH2 is required for proper differentiation of a mature lung secretory cell population during development (Snitow et al. 2015), potentially indicating a role for EZH2 in a seasonal cycle of differentiation through changes in chromatin state. Nineteen other chromatin/ histone modifiers were also identified as differentially expressed in the PT on LP, these include the histone methyltransferase; SUV39H2 (also identified by Lomet et al. 2018), and, histone acetyltransferase; JADE3 (Fig. 4D) (Wood et al. 2015). Furthermore, through its phosphatase activity, EYA3 promotes DNA repair through posttranslational modification of H2A.X to allow recruitment of DNA repair factors (Cook et al. 2009). Characterization of the chromatin state in the PT remains to be investigated in order to test these hypotheses.

As a final point, the role for the tanycytes in the 3rd ventricle (ependymal zone) should not be overlooked. As discussed earlier, the mothers photoperiodic history programmed the trajectory of the offspring's reproductive development and sensitivity to photoperiodic signals, through changes in sensitivity to TSH in the tanycytes not the PT (Sáenz de Miera et al. 2017). In sheep, the reproductive switch-off at the end of the winter breeding season can be blocked by thyroidectomy (THX) with the greatest transcriptional effects in the ependymal zone (Lomet et al. 2018). The hypothalamic region is a known stem cell niche and seasonal remodelling has been observed in the median eminence (ME) of both the quail and sheep (Yamamura et al. 2004, Wood et al. 2015). Therefore, the hypotheses presented here, may also be relevant for timing circuits in the ependymal zone. SHH, a known developmental morphogen, is expressed by the tanycytes in a seasonal manner, suggesting seasonal differentiation either in the ME and/or morphogenic signals from the ME that may signal to the PT. This highlights the potential importance of the interaction between tanycytes and the PT in the generation of a seasonal rhythm. Mathematical modelling to consider sensitivity, cellular plasticity and PT/ tanycyte crosstalk in long-term timing is required.

\section{Conclusions}

The phase of the seasonal cycle is defined by a binary switching of cellular phenotype of the PT-specific thyrotroph to TSH $\beta$-positive and the proportion of cells in that state. Therefore, it is hypothesized that the basis of seasonal rhythm generation is a cellular population-based timer within the PT. A cellular population based timer is used to time seasonal flowering in plants. I propose that the adult PT is a plastic tissue, showing a seasonal cycle of differentiation, and that the underlying processes are likely to be epigenetic. Considering the mechanisms behind adult cellular plasticity offers a framework to hypotheses how a long-term timer functions within the PT. Finally, the PT may offer a unique tissue to explore cellular plasticity in an adult mammal, as no injury or disease state is required to initiate this process.

Declaration of interest

The author declares that there is no conflict of interest that could be perceived as prejudicing the impartiality of this review.

\section{Funding}

S H W is supported by the Tromsø forskningsstiftelse (TFS) starter grant TFS2016SW.

\section{Acknowledgements}

Thanks to Andrew Loudon (University of Manchester) for his mentorship and support since I started in this exciting field of research. I thank David Hazlerigg (University of Tromsø, Norway), for lengthy discussion on this topic and refinement of the hypotheses. 


\section{References}

Aizawa S, Higaki Y, Dudaui A, Nagasaka M, Takahashi S, Sakata I \& Sakai T 2016 Identification of marker genes for pars tuberalis morphogenesis in chick embryo: expression of Cytokine-like 1 and Gap junction protein alpha 5 in pars tuberalis. Cell and Tissue Research 366 721-731. (https://doi.org/10.1007/s00441-016-2484-9)

Akimoto M, Nishimaki T, Arai Y, Uchinuma E, Yamauchi H \& Kameda Y 2010 Hes1 regulates formations of the hypophyseal pars tuberalis and the hypothalamus. Cell and Tissue Research 340 509-521. (https://doi. org/10.1007/s00441-010-0951-2)

Andrés F \& Coupland G 2012 The genetic basis of flowering responses to seasonal cues. Nature Reviews Genetics 13 627-639. (https://doi. org/10.1038/nrg3291)

Angel A, Song J, Dean C \& Howard M 2011 A Polycomb-based switch underlying quantitative epigenetic memory. Nature 476 105-108. (https://doi.org/10.1038/nature10241)

Ashe HL 2006 The interpretation of morphogen gradients. Development 133 385-394. (https://doi.org/10.1242/dev.02238)

Bank JHH, Cubuk C, Wilson D, Rijntjes E, Kemmling J, Markovsky H, Barrett P \& Herwig A 2017 Gene expression analysis and microdialysis suggest hypothalamic triiodothyronine (T3) gates daily torpor in Djungarian hamsters (Phodopus sungorus). Journal of Comparative Physiology B 187 857-868. (https://doi.org/10.1007/s00360-017-1086-5)

Beymer M, Henningsen J, Bahougne T \& Simonneaux V 2016 The role of kisspeptin and RFRP in the circadian control of female reproduction. Molecular and Cellular Endocrinology 438 89-99. (https://doi. org/10.1016/j.mce.2016.06.026)

Billings HJ, Viguié C, Karsch FJ, Goodman RL, Connors JM \& Anderson GM 2002 Temporal requirements of thyroid hormones for seasonal changes in LH secretion. Endocrinology 143 2618-2625. (https://doi.org/10.1210/endo.143.7.8924)

Bittman EL, Karsch FJ \& Hopkins JW 1983 Role of the pineal gland in ovine photoperiodism: regulation of seasonal breeding and negative feedback effects of estradiol upon luteinizing hormone secretion. Endocrinology 113 329-336. (https://doi.org/10.1210/endo-113-1-329)

Butler MP, Turner KW, Park JH, Schoomer EE, Zucker I \& Gorman MR 2010 Seasonal regulation of reproduction: altered role of melatonin under naturalistic conditions in hamsters. Proceedings: Biological Sciences/The Royal Society 277 2867-2874. (https://doi.org/10.1098/rspb.2010.0396)

Cai S, Fu X \& Sheng Z 2007 Dedifferentiation: a new approach in stem cell research. BioScience 57 655-662. (https://doi.org/10.1641/B570805)

Chattwood A, Nagayama K, Bolourani P, Harkin L, Kamjoo M, Weeks G \& Thompson CR 2013 Developmental lineage priming in Dictyostelium by heterogeneous Ras activation. eLife 2 e01067. (https://doi. org/10.7554/eLife.01067)

Cinti F, Bouchi R, Kim-Muller JY, Ohmura Y, Sandoval PR, Masini M, Marselli L, Suleiman M, Ratner LE, Marchetti P, et al. 2016 Evidence of $\beta$-cell dedifferentiation in human type 2 diabetes. Journal of Clinical Endocrinology \& Metabolism 101 1044-1054. (https://doi.org/10.1210/ jc.2015-2860)

Cook PJ, Ju BG, Telese F, Wang X, Glass CK \& Rosenfeld MG 2009 Tyrosine dephosphorylation of H2AX modulates apoptosis and survival decisions. Nature 458 591-596. (https://doi.org/10.1038/ nature07849)

Dardente H 2015 Circannual biology: the double life of the seasonal thyrotroph. Current Biology 25 R988-R991. (https://doi.org/10.1016/j. cub.2015.09.002)

Dardente H, Klosen P, Pévet P \& Masson-Pévet M 2003 MT1 melatonin receptor mRNA expressing cells in the pars tuberalis of the European hamster: effect of photoperiod. Journal of Neuroendocrinology 15 778-786. (https://doi.org/10.1046/j.1365-2826.2003.01060.x)

Dardente H, Wyse CA, Birnie MJ, Dupré SM, Loudon ASI, Lincoln GA \& Hazlerigg DG 2010 A molecular switch for photoperiod responsiveness in mammals. Current Biology 20 2193-2198. (https:// doi.org/10.1016/j.cub.2010.10.048)
Dardente H, Hazlerigg DG \& Ebling FJP 2014 Thyroid hormone and seasonal rhythmicity. Frontiers in Endocrinology 5 19. (https://doi. org/10.3389/fendo.2014.00019)

Dawson A 2015 Annual gonadal cycles in birds: modeling the effects of photoperiod on seasonal changes in GnRH-1 secretion. Frontiers in Neuroendocrinology 37 52-64. (https://doi.org/10.1016/j. yfrne.2014.08.004)

Dunn IC, Wilson PW, Shi Y, Burt DW, Loudon ASI \& Sharp PJ 2017 Diurnal and photoperiodic changes in thyrotrophin-stimulating hormone $\beta$ expression and associated regulation of deiodinase enzymes (DIO2, DIO3) in the female juvenile chicken hypothalamus. Journal of Neuroendocrinology 29 e12554. (https://doi.org/10.1111/ jne.12554)

Ebenhöh O \& Hazlerigg D 2013 Modelling a molecular calendar: the seasonal photoperiodic response in mammals. Chaos, Solitons and Fractals 50 39-47. (https://doi.org/10.1016/j.chaos.2012.11.007)

Eldar A \& Elowitz MB 2010 Functional roles for noise in genetic circuits. Nature 467 167-173. (https://doi.org/10.1038/nature09326)

Featherstone K, Harper CV, McNamara A, Semprini S, Spiller DG, McNeilly J, McNeilly AS, Mullins JJ, White MRH \& Davis JRE 2011 Pulsatile patterns of pituitary hormone gene expression change during development. Journal of Cell Science 124 3484-3491. (https:// doi.org/10.1242/jcs.088500)

Featherstone K, White MRH \& Davis JRE 2012 The prolactin gene: a paradigm of tissue-specific gene regulation with complex temporal transcription dynamics. Journal of Neuroendocrinology 24 977-990. (https://doi.org/10.1111/j.1365-2826.2012.02310.x)

Featherstone K, Hey K, Momiji H, McNamara AV, Patist AL, Woodburn J, Spiller DG, Christian HC, McNeilly AS, Mullins JJ, et al. 2016 Spatially coordinated dynamic gene transcription in living pituitary tissue. eLife 5 e08494. (https://doi.org/10.7554/eLife.08494)

Gordon BS, Delgado Díaz DC, White JP, Carson JA \& Kostek MC 2012 Six1 and Six1 cofactor expression is altered during early skeletal muscle overload in mice. Journal of Physiological Sciences 62 393-401. (https://doi.org/10.1007/s12576-012-0214-y)

Gwinner E 1986 Circannual Rhythms. Berlin Heidelberg: Springer Verlag. Hanon EA, Lincoln GA, Fustin J-M, Dardente H, Masson-Pévet M, Morgan PJ \& Hazlerigg DG 2008 Ancestral TSH mechanism signals summer in a photoperiodic mammal. Current Biology 18 1147-1152. (https://doi.org/10.1016/j.cub.2008.06.076)

Harper CV, Finkenstädt B, Woodcock DJ, Friedrichsen S, Semprini S, Ashall L, Spiller DG, Mullins JJ, Rand DA, Davis JRE, et al. 2011 Dynamic analysis of stochastic transcription cycles. PLoS Biology 9 e1000607. (https://doi.org/10.1371/journal.pbio.1000607)

Hazlerigg D \& Loudon A 2008 New insights into ancient seasonal life timers. Current Biology 18 R795-R804. (https://doi.org/10.1016/j. cub.2008.07.040)

Hazlerigg DG \& Lincoln GA 2011 Hypothesis: cyclical histogenesis is the basis of circannual timing. Journal of Biological Rhythms 26 471-485. (https://doi.org/10.1177/0748730411420812)

Hazlerigg D \& Simonneaux V 2015 Seasonal reproduction in mammals. In Knobil and Neill's Physiology and Reproduction, 4th ed, pp 1575-1660. Eds Plant TM \& Zeleznic AJ. Cambridge, MA, USA: Academic Press.

Hazlerigg D, Lomet D, Lincoln G \& Dardente H 2018 Neuroendocrine correlates of the critical day length response in the Soay sheep. Journal of Neuroendocrinology e12631. (https://doi.org/10.1111/ jne.12631)

Hazlerigg DG, Wyse CA, Dardente H, Hanon EA \& Lincoln GA 2013 Photoperiodic variation in CD45-positive cells and cell proliferation in the mediobasal hypothalamus of the Soay sheep. Chronobiology International 30 548-558. (https://doi.org/10.3109/07420528.2012.7 54450)

Henningsen JB, Gauer F \& Simonneaux V 2016 RFRP neurons - the doorway to understanding seasonal reproduction in mammals. Frontiers in Endocrinology 7 36. (https://doi.org/10.3389/fendo.2016.00036)
(C) 2018 Society for Endocrinology Published by Bioscientifica Ltd. Printed in Great Britain 
Henson JR, Carter SN \& Freeman DA 2013 Exogenous $\mathrm{T}_{3}$ elicits long day-like alterations in testis size and the RFamides Kisspeptin and gonadotropin-inhibitory hormone in short-day Siberian hamsters. Journal of Biological Rhythms 28 193-200. (https://doi. org/10.1177/0748730413487974)

Hey KL, Momiji H, Featherstone K, Davis JRE, White MRH, Rand DA \& Finkenstädt B 2015 A stochastic transcriptional switch model for single cell imaging data. Biostatistics 16 655-669. (https://doi. org/10.1093/biostatistics/kxv010)

Inoue M, Aizawa S, Higaki Y, Kawashima A, Koike K, Takagi H, Sakai T \& Sakata I 2013 Detailed morphogenetic analysis of the embryonic chicken pars tuberalis as glycoprotein alpha subunit positive region. Journal of Molecular Histology 44 401-409. (https://doi.org/10.1007/ s10735-012-9479-y)

Jemc J \& Rebay I 2007 Identification of transcriptional targets of the dualfunction transcription factor/phosphatase eyes absent. Developmental Biology 310 416-429. (https://doi.org/10.1016/j.ydbio.2007.07.024)

Johnston JD, Klosen P, Barrett P \& Hazlerigg DG 2006 Regulation of MT melatonin receptor expression in the foetal rat pituitary. Journal of Neuroendocrinology 18 50-56. (https://doi.org/10.1111/j.13652826.2005.01389.x)

Joost S, Zeisel A, Jacob T, Lö P, Linnarsson S, Kasper M, Sun X \& La Manno G 2016 Single-cell transcriptomics reveals that differentiation and spatial signatures shape epidermal and hair follicle heterogeneity. Cell Systems 3 221-237. (https://doi.org/10.1016/j.cels.2016.08.010)

Jukam D \& Desplan C 2010 Binary fate decisions in differentiating neurons. Current Opinion in Neurobiology 20 6-13. (https://doi. org/10.1016/j.conb.2009.11.002)

Jukam D, Xie B, Rister J, Terrell D, Charlton-Perkins M, Pistillo D, Gebelein B, Desplan C \& Cook T 2013 Opposite feedbacks in the hippo pathway for growth control and neural fate. Science $\mathbf{3 4 2}$ 1238016. (https://doi.org/10.1126/science.1238016)

Kameda Y, Miura M \& Ohno S 1998 Localization and development of chromogranin A and luteinizing hormone immunoreactivities in the secretory-specific cells of the hypophyseal pars tuberalis of the chicken. Histochemistry and Cell Biology 109 211-222. (https://doi. org/10.1007/s004180050220)

Kay RR \& Thompson CRL 2009 Forming patterns in development without morphogen gradients: scattered differentiation and sorting out. Cold Spring Harbor Perspectives in Biology 1 a001503. (https://doi. org/10.1101/cshperspect.a001503)

Khazaei MR, Bunk EC, Hillje A-L, Jahn HM, Riegler EM, Knoblich JA, Young P \& Schwamborn JC 2011 The E3-ubiquitin ligase TRIM2 regulates neuronal polarization. Journal of Neurochemistry 117 29-37. (https://doi.org/10.1111/j.1471-4159.2010.06971.x)

Kita A, Imayoshi I, Hojo M, Kitagawa M, Kokubu H, Ohsawa R, Ohtsuka T, Kageyama R \& Hashimoto N 2007 Hes1 and Hes5 control the progenitor pool, intermediate lobe specification, and posterior lobe formation in the pituitary development. Molecular Endocrinology 21 1458-1466. (https://doi.org/10.1210/me.2007-0039)

Klosen P, Bienvenu C, Demarteau O, Dardente H, Guerrero H, Pévet P \& Masson-Pévet M 2002 The mt1 melatonin receptor and RORbeta receptor are co-localized in specific TSH-immunoreactive cells in the pars tuberalis of the rat pituitary. Journal of Histochemistry and Cytochemistry 50 1647-1657. (https://doi. org/10.1177/002215540205001209)

Klosen P, Sébert M-E, Rasri K, Laran-Chich M-P \& Simonneaux V 2013 TSH restores a summer phenotype in photoinhibited mammals via the RF-amides RFRP3 and kisspeptin. FASEB Journal 27 2677-2686. (https://doi.org/10.1096/fj.13-229559)

Korf H-W 2018 Signaling pathways to and from the hypophysial pars tuberalis, an important center for the control of seasonal rhythms. General and Comparative Endocrinology 258 236-243. (https://doi. org/10.1016/j.ygcen.2017.05.011)

Kozmik Z, Holland ND, Kreslova J, Oliveri D, Schubert M, Jonasova K, Holland LZ, Pestarino M, Benes V \& Candiani S 2007 Pax-Six-Eya-
Dach network during amphioxus development: conservation in vitro but context specificity in vivo. Developmental Biology 306 143-159. (https://doi.org/10.1016/j.ydbio.2007.03.009)

Kriegsfeld LJ 2006 Driving reproduction: RFamide peptides behind the wheel. Hormones and Behavior 50 655-666. (https://doi.org/10.1016/j. yhbeh.2006.06.004)

Kumar JP 2009 The molecular circuitry governing retinal determination. Biochimica et Biophysica Acta: Gene Regulatory Mechanisms 1789 306-314. (https://doi.org/10.1016/j.bbagrm.2008.10.001)

Li Y, Donmez N, Sahinalp C, Xie N, Wang Y, Xue H, Mo F, Beltran H, Gleave M, Wang Y, et al. 2017 SRRM4 drives neuroendocrine transdifferentiation of prostate adenocarcinoma under androgen receptor pathway inhibition. European Urology 71 68-78. (https://doi. org/10.1016/j.eururo.2016.04.028)

Lincoln GA 2006 Melatonin entrainment of circannual rhythms. Chronobiology International 23 301-306. (https://doi. org/10.1080/07420520500464452)

Lincoln GA \& Clarke IJ 1994 Photoperiodically-lnduced cycles in the secretion of prolactin in hypothalamo-pituitary disconnected rams: evidence for translation of the melatonin signal in the pituitary gland. Journal of Neuroendocrinology 6 251-260. (https://doi. org/10.1111/j.1365-2826.1994.tb00580.x)

Lincoln G, Messager S, Andersson H \& Hazlerigg D 2002 Temporal expression of seven clock genes in the suprachiasmatic nucleus and the pars tuberalis of the sheep: evidence for an internal coincidence timer. PNAS 99 13890-13895. (https://doi.org/10.1073/ pnas.212517599)

Lincoln GA, Andersson H \& Loudon A 2003 Clock genes in calendar cells as the basis of annual timekeeping in mammals - a unifying hypothesis. Journal of Endocrinology 179 1-13. (https://doi. org/10.1677/joe.0.1790001)

Lincoln GA, Johnston JD, Andersson H, Wagner G \& Hazlerigg DG 2005 Photorefractoriness in mammals: dissociating a seasonal timer from the circadian-based photoperiod response. Endocrinology 146 3782-3790. (https://doi.org/10.1210/en.2005-0132)

Lincoln GA, Clarke IJ, Hut RA \& Hazlerigg DG 2006 Characterizing a mammalian circannual pacemaker. Science 314 1941-1944. (https:// doi.org/10.1126/science.1132009)

Loft A, Forss I, Siersbæk MS, Schmidt SF, Larsen A-SB, Madsen JGS, Pisani DF, Nielsen R, Aagaard MM, Mathison A, et al. 2015 Browning of human adipocytes requires KLF11 and reprogramming of PPAR $\gamma$ superenhancers. Genes and Development 29 7-22. (https://doi. org/10.1101/gad.250829.114)

Lomet D, Cognié J, Chesneau D, Dubois E, Hazlerigg D \& Dardente H 2018 The impact of thyroid hormone in seasonal breeding has a restricted transcriptional signature. Cellular and Molecular Life Sciences 75 905-919. (https://doi.org/10.1007/s00018-017-2667-x)

Majumdar G, Yadav G, Rani S \& Kumar V 2014 A photoperiodic molecular response in migratory redheaded bunting exposed to a single long day. General and Comparative Endocrinology 204 104-113. (https://doi.org/10.1016/j.ygcen.2014.04.013)

Masumoto K, Ukai-Tadenuma M, Kasukawa T, Nagano M, Uno KD, Tsujino K, Horikawa K, Shigeyoshi Y \& Ueda HR 2010 Acute induction of Eya3 by late-night light stimulation triggers TSH $\beta$ expression in photoperiodism. Current Biology 20 2199-2206. (https:// doi.org/10.1016/j.cub.2010.11.038)

Migaud M, Batailler M, Pillon D, Franceschini I \& Malpaux B 2011 Seasonal changes in cell proliferation in the adult sheep brain and pars tuberalis. Journal of Biological Rhythms 26 486-496. (https://doi. org/10.1177/0748730411420062)

Milesi S, Simonneaux V \& Klosen P 2017 Downregulation of Deiodinase 3 is the earliest event in photoperiodic and photorefractory activation of the gonadotropic axis in seasonal hamsters. Scientific Reports $\mathbf{7}$ 17739. (https://doi.org/10.1038/s41598-017-17920-y)

Morgan PJ, Barrett P, Howell HE \& Helliwell R 1994 Melatonin receptors: localization, molecular pharmacology and physiological http://joe.endocrinology-journals.org

https://doi.org/10.1530/JOE-18-0177 (c) 2018 Society for Endocrinology Published by Bioscientifica Ltd. Printed in Great Britain 
significance. Neurochemistry International 24 101-146. (https://doi. org/10.1016/0197-0186(94)90100-7)

Murphy M, Jethwa PH, Warner A, Barrett P, Nilaweera KN, Brameld JM \& Ebling FJP 2012 Effects of manipulating hypothalamic triiodothyronine concentrations on seasonal body weight and torpor cycles in Siberian hamsters. Endocrinology 153 101-112. (https://doi. org/10.1210/en.2011-1249)

Nakane Y \& Yoshimura T 2014 Universality and diversity in the signal transduction pathway that regulates seasonal reproduction in vertebrates. Frontiers in Neuroscience 8 115. (https://doi.org/10.3389/ fnins.2014.00115)

Nakao N, Ono H, Yamamura T, Anraku T, Takagi T, Higashi K, Yasuo S, Katou Y, Kageyama S, Uno Y, et al. 2008 Thyrotrophin in the pars tuberalis triggers photoperiodic response. Nature $\mathbf{4 5 2} 317-322$. (https://doi.org/10.1038/nature06738)

O'Neill MC \& Stockdale FE 1972 Differentiation without cell division in cultured skeletal muscle. Developmental Biology 29 410-418. (https:// doi.org/10.1016/0012-1606(72)90081-4)

Ono H, Hoshino Y, Yasuo S, Watanabe M, Nakane Y, Murai A, Ebihara S, Korf H-W \& Yoshimura T 2008 Involvement of thyrotropin in photoperiodic signal transduction in mice. PNAS 105 18238-18242. (https://doi.org/10.1073/pnas.0808952105)

Paksa A \& Rajagopal J 2017 The epigenetic basis of cellular plasticity. Current Opinion in Cell Biology 49 116-122. (https://doi.org/10.1016/J. CEB.2018.01.003)

Petri I, Diedrich V, Wilson D, Fernández-Calleja J, Herwig A, Steinlechner S \& Barrett P 2016 Orchestration of gene expression across the seasons: hypothalamic gene expression in natural photoperiod throughout the year in the Siberian hamster. Scientific Reports 6 29689. (https://doi.org/10.1038/srep29689)

Raetzman LT, Cai JX \& Camper SA 2007 Hes1 is required for pituitary growth and melanotrope specification. Developmental Biology 304 455-466. (https://doi.org/10.1016/j.ydbio.2006.11.010)

Ross AW, Helfer G, Russell L, Darras VM \& Morgan PJ 2011 Thyroid hormone signalling genes are regulated by photoperiod in the hypothalamus of F344 rats. PLOS ONE 6 e21351. (https://doi. org/10.1371/journal.pone.0021351)

Sáenz de Miera C, Hanon EA, Dardente H, Birnie M, Simonneaux V, Lincoln GA \& Hazlerigg DG 2013 Circannual variation in thyroid hormone deiodinases in a short-day breeder. Journal of Neuroendocrinology 25 412-421. (https://doi.org/10.1111/jne.12013)

Sáenz de Miera C, Monecke S, Bartzen-Sprauer J, Laran-Chich M-P, Pévet P, Hazlerigg DG \& Simonneaux V 2014 A circannual clock drives expression of genes central for seasonal reproduction. Current Biology 24 1500-1506. (https://doi.org/10.1016/j.cub.2014.05.024)

Sáenz de Miera C, Bothorel B, Jaeger C, Simonneaux V \& Hazlerigg D 2017 Maternal photoperiod programs hypothalamic thyroid status via the fetal pituitary gland. PNAS 114 8408-8413. (https://doi. org/10.1073/pnas.1702943114)

Shen C-N, Burke ZD \& Tosh D 2004 Transdifferentiation, metaplasia and tissue regeneration. Organogenesis 1 36-44. (https://doi.org/10.4161/ org.1.2.1409)

Simonneaux V, Ancel C, Poirel VJ \& Gauer F 2013 Kisspeptins and RFRP-3 act in concert to synchronize rodent reproduction with seasons. Frontiers in Neuroscience 7 22. (https://doi.org/10.3389/fnins.2013.00022)

Snitow ME, Li S, Morley MP, Rathi K, Lu MM, Kadzik RS, Stewart KM \& Morrisey EE 2015 Ezh2 represses the basal cell lineage during lung endoderm development. Development 142 108-117. (https://doi. $\operatorname{org} / 10.1242 /$ dev.116947)
Song J, Angel A, Howard M \& Dean C 2012 Vernalization - a coldinduced epigenetic switch. Journal of Cell Science 125 3723-3731. (https://doi.org/10.1242/jcs.084764)

Song J, Irwin J \& Dean C 2013 Remembering the prolonged cold of winter. Current Biology 23 R807-R811. (https://doi.org/10.1016/j. cub.2013.07.027)

Stoeckel E, Hindelang C, Klein M-J, Poissonnier M \& Félix J-M 1993 Early expression of the glycoprotein hormone alpha-subunit in the pars tuberalis of the rat pituitary gland during ontogenesis. Neuroendocrinology 58 616-624. (https://doi.org/10.1159/000126600)

Tadjuidje E \& Hegde RS 2013 The eyes absent proteins in development and disease. Cellular and Molecular Life Sciences 70 1897-1913. (https://doi.org/10.1007/s00018-012-1144-9)

Talchai C, Xuan S, Lin HV, Sussel L \& Accili D 2012 Pancreatic $\beta$ cell dedifferentiation as a mechanism of diabetic $\beta$ cell failure. Cell $\mathbf{1 5 0}$ 1223-1234. (https://doi.org/10.1016/j.cell.2012.07.029)

Teo AKK, Lim CS, Cheow LF, Kin T, Shapiro JA, Kang N-Y, Burkholder W \& Lau HH 2018 Single-cell analyses of human islet cells reveal de-differentiation signatures. Cell Death Discovery 4 14. (https://doi. org/10.1038/s41420-017-0014-5)

Wang Z, York NW, Nichols CG \& Remedi MS 2014 Pancreatic $\beta$ cell dedifferentiation in diabetes and redifferentiation following insulin therapy. Cell Metabolism 19 872-882. (https://doi.org/10.1016/j. cmet.2014.03.010)

West AC \& Wood SH 2018 Seasonal physiology: making the future a thing of the past. Current Opinion in Physiology 5 1-8. (https://doi. org/10.1016/j.cophys.2018.04.006)

Wood S \& Loudon A 2014 Clocks for all seasons: unwinding the roles and mechanisms of circadian and interval timers in the hypothalamus and pituitary. Journal of Endocrinology 222 R39-R59. (https://doi. org/10.1530/JOE-14-0141)

Wood S \& Loudon A 2017 The pars tuberalis: the site of the circannual clock in mammals? General and Comparative Endocrinology 258 222-235. (https://doi.org/10.1016/j.ygcen.2017.06.029)

Wood SH, Christian HC, Miedzinska K, Saer BRC, Johnson M, Paton B, Yu L , McNeilly J, Davis JRE, McNeilly AS, et al. 2015 Binary switching of calender cells in the pituitary defines the phase of the circannual cycle in mammals. Current Biology 25 2651-2662. (https://doi. org/10.1016/j.cub.2015.09.014)

Woodfill CJ, Wayne NL, Moenter SM \& Karsch FJ 1994 Photoperiodic synchronization of a circannual reproductive rhythm in sheep: identification of season-specific time cues. Biology of Reproduction $\mathbf{5 0}$ 965-976. (https://doi.org/10.1095/biolreprod50.4.965)

Xie J, Wang W-Q, Liu T-X, Deng M \& Ning G 2008 Spatio-temporal expression of chromogranin A during zebrafish embryogenesis. Journal of Endocrinology 198 451-458. (https://doi.org/10.1677/JOE-08-0221)

Xu PX, Cheng J, Epstein JA \& Maas RL 1997 Mouse Eya genes are expressed during limb tendon development and encode a transcriptional activation function. PNAS 94 11974-11979. (https:// doi.org/10.1073/pnas.94.22.11974)

Yamamura T, Hirunagi K, Ebihara S \& Yoshimura T 2004 Seasonal morphological changes in the neuro-glial interaction between gonadotropin-releasing hormone nerve terminals and glial endfeet in Japanese quail. Endocrinology 145 4264-4267. (https://doi. org/10.1210/en.2004-0366)

Yang Y, Tung JW, Ghosn EEB, Herzenberg LA \& Herzenberg LA 2007 Division and differentiation of natural antibody-producing cells in mouse spleen. PNAS 104 4542-4546. (https://doi.org/10.1073/ pnas.0700001104)

Received in final form 19 July 2018

Accepted 31 July 2018

Accepted Preprint published online 2 August 2018 http://joe.endocrinology-journals.org https://doi.org/10.1530/JOE-18-0177
(C) 2018 Society for Endocrinology Published by Bioscientifica Ltd. Printed in Great Britain 